\title{
Exemplo lexicográfico em dicionários escolares brasileiros
}

Antonio Luciano Pontes*

RESUMO: Exemplo lexicográfico é aqui concebido sob a perspectiva da metalexicografia e da teoria da multimodalidade. a escolha deste estudo se justifica pela importância dos exemplos como paradigma informacional, pois assumem variadas funções comunicativas na composição do verbete lexicográfico. O estudo tem como objetivo classificar e analisar as funções do exemplo lexicográfico em dicionários escolares brasileiros. Para empreender a pesquisa, tomo por base o estudo de Hernández (1994), de Humblé (2001), de Pérez (2000), de Calderón Campos (1994). Para análise da face visual do exemplo, levo em conta as contribuições dos teóricos ligados à teoria da multimodalidade, como Kress e Leeuwen (2006). O material de estudo é formado por dicionários adotados na escola de ensino fundamental, como: Ferreira (2001, 2005), Mattos (2005), Aulete (2004) e Rocha (2004).

Palavras-chave: Exemplo lexicográfico; metalexicografia; função comunicativa; teoria da multimodalidade.

ABSTRACT: Lexicographical example is conceived here under the perspective of metalexicography and the multimodality theory. The choice for this study is justified from the importance of examples as informational paradigm as they assume varied communicative functions when composing the lexicographical article. The study's objective is to classify and analyze functions of the lexicographical example in Brazilian school dictionaries. In order to carry out the research I rely on the studies of Hernández (1994), Humble (2001), Pérez (2000), Calderón Campos (1994). Towards the visual analysis of the example I consider the contributions of scholars linked to the theory of multimodality, like Kress and van Leeuwen (2006). The corpus studied consists of dictionaries such as: Ferreira (2001, 2005), Mattos (2005), Aulete (2004), Rocha (2004) used in the primary education school.

Keywords: Lexicographical example; metalexocography; communicative function; multimodality theory.

\footnotetext{
Universidade Estadual do Ceará. E-mail: pontes321@hotmail.com.
} 
1. Considerações iniciais

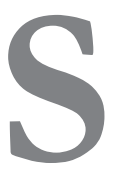

egundo Auroux (1992: 65), o dicionário, como tecnologia, descreve e instrumentaliza uma língua e, ainda hoje, é considerado um dos pilares de nosso saber metalinguístico. É necessário, portanto, que estudos sejam realizados, reconhecendo o dicionário como objeto multifacetado, do qual resultam várias formas de examiná-lo sob diferentes perspectivas. Ou, parafraseando Gelpí Arroyo (2000), um dicionário é, por natureza, um produto poliédrico porque são múltiplos os pontos de vista sob os quais se pode descrevê-lo.

Estudarei aqui o exemplo lexicográfico sob a perspectiva da Metalexicografia e da Teoria da Multimodalidade. A escolha deste estudo se justifica pela importância dos exemplos como paradigma informacional, uma vez que assumem variadas funções comunicativas na composição do verbete lexicográfico. Conforme observa Santos (2006: 28), os lexicógrafos começaram a se interessar pelo exemplo somente depois da Segunda Guerra Mundial, principalmente após a publicação do Oxford Advanced Learners's Dictionary (OALD), de Hornby (1948).

Meu objetivo, então, é classificar e analisar as funções do exemplo lexicográfico em dicionários escolares brasileiros. Para empreender o estudo, tomo por base a Teoria Metalexicográfica, que dá sustentação aos estudos em torno de questões relativas ao tema, como o estudo de Hernández (1994), de Humblé (2001), de Pérez (2000), de Forgas Berdet (1996) e de Calderón Campos (1994). Para análise da face visual do paradigma informacional em questão, tomo por base as contribuições dos teóricos ligados à Teoria da Multimodalidade (Kress E Van Leeuwen, 2006).

O material em estudo é composto por alguns do dicionários escolares avaliados e indicados pelo Programa Nacional do Livro Didático (PNLD) para o Ensino Fundamental II, como: Ferreira (2001, 2005), Bueno (2000), Mattos (2005), Aulete (2004) e Rocha (2004).

\section{Pressupostos teóricos}

Para fundamentar a análise, discorro sobre aspectos relativos ao funcionamento do verbete, defino o exemplo lexicográfico, e, em seguida, defendo sua importância no contexto de dicionário escolar, por natureza, híbrido de dicionário de recepção e de produção. 
2.1.Aspectos semânticos e pragmáticos do texto-verbete

O verbete lexicográfico se constitui de informações semânticas e pragmáticas, que se integram e se complementam na construção do sentido. Em outras palavras, os paradigmas informacionais são significativos na medida em que se definem como categorias dinâmicas e difusas, não sendo, pois, nem o exemplo nem a definição ou outro paradigma, per si, suficiente e absoluto em um texto lexicográfico.

Rey Debove (1971) sustenta tal verdade, quando afirma que a definição incompleta, apoiada em exemplos, torna-se completa semanticamente graças ao exemplo que a acompanha. O exemplo, no entanto, muitas vezes, pode também ilustrar a unidade lexical em uso.

Assim, o exemplo lexicográfico expressa traços semânticos e informações pragmáticas integrados entre si e, por vezes, integrados a outros paradigmas no interior do verbete, caracterizando-o como texto. Essa linha de pensamento coincide com a de Gelpí e Castillo (2004) ao afirmarem que a transmissão do significado da unidade contida no dicionário é de responsabilidade do verbete lexicográfico e não só da definição, nem tampouco do exemplo lexicográfico. Por outro lado, segundo as mesmas autoras, deve-se levar em consideração que o sentido é transmitido por e no verbete. Na realidade, pode-se partir da suposição de que considerar que a transmissão de sentido realizada por meio do verbete completo seja uma opção lexicograficamente produtiva, porque o peso da transmissão do conhecimento fica integrado a todo o verbete. A partir desse pressuposto, Gelpí e Castillo (2004: 132) afirmam que todos os paradigmas no verbete são responsáveis pela construção da informação: "A informação é transmitida a partir de um ou mais de um tipo de indicações. São indicações a definição, os exemplos, as marcas gramaticais e pragmáticas, entre outras". Por isso, os paradigmas, em geral, se cruzam, se superpõem e, raramente, se distinguem com objetividade.

Agora, discutirei o exemplo lexicográfico como um paradigma importante na construção do sentido em um texto-verbete, pelas várias funções comunicativas que assume e pelos aspectos gramaticais e ideológicos que representa. No entanto, para Pérez (2000), tais informações deverão ser adaptadas à compreensão do usuário ao qual se destina o dicionário para não pecar nem pela trivialidade nem pelo grau excessivo de especialização.

\subsection{O exemplo lexicográfico: como se caracteriza}

O exemplo lexicográfico é um enunciado que se acrescenta à definição para comprovar, ilustrar ou abordar uma palavra-entrada. Enquanto a 
definição constitui um modelo geral e abstrato, os exemplos se comportam como modelos concretos, que servem ao usuário do dicionário para repeti-los ou para formar enunciados paralelos com o aval de um modelo de construção atual e culto (Hernández, 1994: 112). O exemplo, contudo, não deve ser considerado menos importante do que a definição, uma simples informação adicional ao verbete lexicográfico; ao contrário, afirma Hernández (1994: 112), que o exemplo de uso deveria ser o ponto de partida da definição e não simplesmente a prova de sua validade, mas uma parte integrante do verbete; acrescenta, ainda: "Considerados como complementos, como meros acessórios - que, como tais, poderiam omitir-se - seria o mesmo que reconhecer que o dicionário é só uma obra com finalidade decodificadora"; ou seja, uma obra cuja função seria apenas a de ajudar o leitor a compreender os textos que leem.

O exemplo lexicográfico, no entanto, está intimamente relacionado com a capacidade de produção das obras de consulta; aliás, a ausência quase total de exemplos é uma das maiores insuficiências da lexicografia escolar brasileira. Por isso, está longe de uma obra dessa natureza cumprir suas funções codificadora (de produção) e decodificadora (de compreensão) que se lhes pode exigir Os exemplos são fundamentais para contextualizar a unidade léxica que representa a entrada.

Os dicionários incluem exemplos, que aparecem de forma assistemática em alguns e sistemática em outros. Esta, porém, não deve ser a questão. $\mathrm{O}$ importante é que eles apareçam com finalidade ou função comunicativa no interior do texto-verbete. Deverão ser descartados, portanto, os exemplos que não signifiquem, que possam causar pistas perdidas ou que apresentem contradições em relação a sua definição. Há também aqueles que aparecem como adorno, incluídos simplesmente porque há um consenso de que os exemplos de uso são importantes nos dicionários escolares.

Sem dúvida, falha o autor que não apresenta exemplos. Um dicionário, para se autodenominar escolar, não pode deixar de apresentá-los, uma vez que sua função é concretizar o significado veiculado em uma definição, que se caracteriza pela abstração de seu conteúdo. Desse modo, o dicionário cumpre principalmente as funções relacionadas à produção.

\section{Exemplo lexicográfico e tipologia de dicionário}

Nem todos os tipos de dicionários têm que, necessariamente, contemplar exemplos em sua microestrutura. Um dicionário definitório, que se destina apenas à leitura pode não conter exemplos e ser, não obstante, um bom dicionário, mas nem um dicionário de uso, nem um dicionário monolíngue 
para estrangeiros, nem um dicionário escolar, podem ser considerados dicionários de qualidade aceitável se não incluírem exemplos em suas acepções, como já assinalado antes. Santamaría Pérez (2000) chega a afirmar que, no caso dos dicionários de produção, é imprescindivel que cada acepção venha acompanhada de exemplos, que, às vezes, auxiliam na compreensão do significado; outras vezes, mostram o comportamento sintático da palavra e também ilustram determinadas colocações.

Colocação é aqui entendida tal como define Porto Dapena ${ }^{1}$ (s/d): associação frequente, no plano sintagmático, de uma palavra com outra ou outras, conservando cada uma delas sua autonomia semântica (no que se diferenciam das expressões fixas, que têm significado global) e, ao mesmo tempo, sem ser mutuamente exigidas, como ocorre no caso das solidariedades.

Para o dicionário bilíngue, (Santamaría Pérez, 2000: 202) distingue apenas duas funções gerais para os exemplos:

a.

\section{Função linguística.}

Ilustrar as construções e combinações mais usuais, além de precisar mais o conteúdo dessa unidade;

b. Função filológica.

Servir como testemunho de uma unidade léxica em uso e um testemunho cultural, pois carrega marcas históricas e ideológicas.

Santamaría Pérez (2000) propõe esses tipos de exemplos para o dicionário bilíngue, entendendo que, nesse dicionário, o exemplo tem funções mais voltadas para os traços culturais e sintáticos, pois aquelas funções são fundamentais ao aprendiz de uma língua estrangeira.

Martin-Rouledge (1997: 181) reconhece a importância do exemplo, mas adianta que isso depende, em parte, do tipo de dicionário, de seu volume e da entrada em si. No caso particular do dicionário escolar, o exemplo ainda se justifica como fundamental por sua importância como ferramenta pedagógica para decodificação e produção de textos, e para aquisição de conhecimentos enciclopédicos que são requeridos ao estudante em seu cotidiano de pesquisa escolar. Por essas razões, os exemplos são necessários aos

[...] entendemos por colocación la asociación frecuente, en el plano sintagmático, de una palabra con otra u otras, conservando cada una de ellas su autonomía semántica (en lo que se diferencian de las expresiones fijas, que tienen un significado global) y, al mismo tiempo, sin ser mutuamente exigidas, como ocurre en el caso de las solidaridades. (tradução minha) 
usuários e nunca deverão se comportar como meros acessórios em relação às outras informações presentes no texto-verbete.

\subsection{Análise do Material Coletado}

Inicialmente, classifico o exemplo sob vários critérios, a partir do material coletado. Na sequência, descrevo-o à luz dos fundamentos da Teoria da Multimodalidade e, por último, teço alguns comentários sobre o funcionamento do exemplo em verbetes de dicionário escolar.

\section{Tipos de exemplos}

A classificação de exemplos fundamenta-se em vários critérios:

\section{A. Quanto à função}

A função preponderante de um exemplo depende do tipo de dicionário no qual ele é encontrado (Humblé, 2001). Com base em Humblé2 (2001: 61), classificam-se os exemplos em dois tipos fundamentais:

A.1. Os exemplos para a leitura

Assumem os seguintes objetivos no interior do verbete.

- Dar conta do sentido que uma palavra tem, explicando-a ou aclarando-a pela via do exemplo:

ir. Dirigir-se (algum lugar com a intenção de permanecer): Vou para São Paulo, lá terei maiores oportunidades.

hiato. Encontro de duas vogais, cada uma em uma sílaba - A palavra saúde tem um hiato.

Imerecido. Que a pessoa não merece: não merecido - Aquele escritor recebeu um

prêmio imerecido: seu trabalho não era o melhor de todos. (Mattos, 2005)

- Distinguir uma acepção das outras:

2 Humblé classifica os exemplos em examples for decoding (de definição) e examples for encoding (de produção). 
Fibra 1. Anat.Bot. Qualquer das estruturas alongadas agrupadas em feixe que constituem tecido animal ou vegetal (fibra muscular): alimento rico em fibras. 2. Fio ou filamento de material diverso: fibra de vidro. (Aulete, 2004)

- Incluir certas orientações ideológicas:

Abocanhar. Tomar alguma coisa para si: abiscoitar, apoderar-se, apossar-se - A nova direção da fábrica de brinquedos espera abocanbar em breve a maior parte do mercado. (Mattos, 2005)

- Apresentar informações enciclopédicas (informações históricas e culturais), ou seja, o exemplo pode servir de veículo para a transmissão indireta de dados culturais e sociais ${ }^{3}$ (Lara, 1992, citado por Escribano, 2003: 122):

Ca.cau. Fruto do cacaueiro, de cujas sementes se faz o chocolate. O Brasil é o $2^{\circ}$ maior produtor mundial de cacau, com 349 mil toneladas (14,1\% do total). (Rocha, 2005);

Física. Ciência que estuda as propriedades da matéria e as suas leis - O estudo do átomo pertence à Física. (Mattos, 2005)

- Acrescentar à definição informações semânticas:

Hiato. Espaço vazio entre dois espaços: intervalo, lacuna - Sempre há um grande intervalo entre uma e outra visita dele. (Mattos, 2005).

Sobre a importância do exemplo, é pertinente afirmar que, no dicionário escolar, um exemplo deveria ter sempre uma razão de ocorrer, pois mesmo que não tenha função para fins de compreensão, pode servir para auxiliar a produção; pode, ainda, funcionar para os dois casos, sendo, portanto, multifuncional.

3 Os aspectos gramaticais predominam nos exemplos de verbos, de adjetivos, de advérbios..., enquanto que os contextos culturais são mais freqüentes nos exemplos de nomes (Garriga Escribano: 122).(tradução minha) 


\section{A.2. Os exemplos para a produção textual}

Além de o exemplo de uso assumir a função de recepção, como foi apresentada acima, funciona com a finalidade de auxiliar o consulente em suas produções de enunciados. Daí denominar-se exemplo de produção, que se define como informações sintático-semânticas e pragmáticas. Essas assumem vários objetivos, muitas vezes, confundindo-se multifuncionalmente:

- Incluir a palavra em um determinado contexto, assegurando a informação sintática necessária sobre restrições seletivas (tal verbo tem sempre um sujeito animado, tal adjetivo se emprega só em tais contextos, por exemplo), mostrando ao leitor enunciados que sugerem determinadas relações (Baylon \& Fabre, 1994: 203):

bal.de.ar 6. Transferir-se, deslocar-se: Os alunos baldearam-se para a sala de aula.

- Suprir as explicações gramaticais, assinalando, por exemplo, o regime dos verbos, o possível uso como adjetivo de um lema categorizado como pronome, a regência preposicional de certos advérbios, o uso transitivo ou intransitivo dos verbos e sua pronominalização (Berdet, 1996):

assistir. 6. Acompanhar na qualidade de ajudante, assistente, assessor: Assistia a(o) imperador desde a infância. (Ferreira, 2001)

- Mostrar a palavra-entrada no contexto:

(11) o.ca.si:o.nar. 1. Causar, motivar: $A$ desatenção ao volante pode ocasionar acidentes graves. (Ferreira, 2001)

- Indicar o uso de colocações típicas: "a colocação que se considera mais útil é a do verbo + substantivo, as de adjetivo + substantivo, ou vice-versa" (Pérez, 2000: 50):

isócrono. Diz-se de dois ou mais acontecimentos, ações, etc., que se dão ao mesmo tempo, ou em intervalos de tempos iguais: movimentos isócronos. (Ferreira, 2001)

- Ilustrar modelos gramaticais: 
homicida. amf ou smf. 1. Que mata outra pessoa - o assaltante homicida foi preso. O homicida foi preso. (Mattos, 2005)

- Indicar registros ou níveis estilísticos:

ir. fig. Passar gradualmente: Seus pensamentos iam da mais profunda tristeza a uma alegria contagiante. (Ferreira, 2001)

- Atestar o uso real das expressões linguísticas, mas não só o "bom uso":

ir. Ir ter com. Ir ao encontro de, encontrar-se: No dia seguinte, foi ter com o irmão. (Ferreira, 2001)

Se quisermos que um dicionário cumpra sua função codificadora - a de ajudar crianças a produzir textos orais ou escritos -, é imprescindivel que cada uma das acepções seja ilustrada através de exemplos, para aclarar melhor a significação, para mostrar o comportamento sintático das palavras, ou, ainda, para ilustrar as combinações léxicas usuais. Segundo Pérez (2000: 51), o exemplo serve, em muitos casos, para complementar a informação contida na definição; ademais, ao mostrar a palavra em um contexto concreto, pode revelar manifestações de uso que a afetam, assim como suas particularidades gramaticais, além de indicar as palavras que se combinam habitualmente com o lema.

\section{B. Quanto à seleção do material}

Os exemplos podem ser extraídos de corpora textuais, orais ou escritos (exemplos autênticos), podem ser inventados (exemplos fabricados) ou ainda baseados em um corpus, mas adaptados pelo lexicógrafo (exemplos adaptados):

Exemplos autênticos. São os selecionados a partir de corpora. Esses exemplos recolhidos de corpora podem ser, por sua vez, de textos escritos, literários ou não, e de textos orais.

Segundo Martinez de Sousa (1995: 174), os exemplos autênticos são extraídos de uma documentação cujas palavras, sintagmas ou fraseologias deveriam tomar-se:

- do estilo informal: corpus de concordância, formado por textos conversacionais, entrevistas veiculadas pelo rádio ou pela televisão; 
- da literatura, a clássica, para os aspectos históricos; e a moderna, para os aspectos modernos;

- das publicações: em especial, as veiculadas na imprensa (revistas e jornais).

Deve-se afirmar, com base em Pérez (2000: 49), que "as citações literárias raramente funcionam eficazmente como exemplos, pois não revelam o uso normal de uma comunidade". E acrescenta:

\footnotetext{
Há duas exceções que justificariam a presença do exemplo literário, apenas nos casos: 1) O melhor modo de exemplificar os casos das figuras retóricas é incluir uma mostra na qual apareça tal figura; 2) se um lema está marcado com a restrição literário ou poético, seria oportuno que o exemplo procedesse de uma fonte literária. (Pérez, 2000: 49) (tradução minha)
}

Lara (1992, citado por Escribano, 2003: 120) comunga com a posição de Pérez (2000), quando critica a presença dos exemplos literários. Segundo Lara (1992), a língua literária se impunha como modelo para a sociedade, perdendo legitimação o uso comum. Felizmente, os dicionários brasileiros estão reduzindo o número de exemplos literários, o que foi observado comparando as edições do Aurélio escolar, da primeira edição até a última. Para ilustrar a natureza do exemplo literário, colhi, em Ferreira (2001), os seguintes:

gris 1. cinzento (1) tirante a azul: "O deslocamento daquelas paragens grises, o salseiro do mar e das chuvas." (Vitoriano Nemésio, A Mocidade de Herculano.)

Nesse verbete, o exemplo funciona simplesmente como abonação de um modelo de "bom uso", seguindo o modelo da gramática tradicional, segundo o qual o melhor uso de linguagem é o da Literatura Clássica. Aliás, em Ferreira (2001), o exemplo literário, em geral, como autêntico, é o predominante e funciona apenas como modelo de norma prescritiva ou registro filológico de uma unidade lexical, já caindo em desuso.

Ainda de Ferreira (2001), apresento mais um exemplo para abonar a entrada do verbete como modelo de bom uso de língua. Desta feita, o autor extraio da "boa literatura" moderna com o objetivo de testemunhar um uso de língua-padrão, que deve servir de modelo da língua.

ha.ver 5.existir(1): "Entre os quadrinhos que adornam as paredes do meu apartamento há um que me desperta particular ternura." (Manuel Bandeira, Andorinba, Andorinba) 
Felizmente, parece que os dicionários brasileiros começam a reduzir o número de exemplos literários de seus dicionários. Em Ferreira (2008), os exemplos literários desaparecem quase por completo, demonstrando, assim, que os dicionários brasileiros assumem as contribuições de novas disciplinas linguísticas, como a Linguística Textual, a Sociolinguística, a Análise da Conversação e outras de orientação pragmática.

Exemplos fabricados (inventados ou construídos). Nesse caso, o dicionarista cria seus próprios enunciados, gera seu próprio corpus de exemplo, tomados diretamente de sua competência lexical.

Quando inventados, os exemplos são criados pelo lexicógrafo. Um exemplo, extraído de Mattos (2005):

Accessível. amf. A que se pode chegar - uma montanha accessivel. Superl.: accessibilissimo. Ant.: inaccessivel.

Ferreira (2005), por exemplo, apresenta um número razoavelmente pequeno de exemplos do tipo inventado, grafados em itálicos, e, menor ainda, é o número de exemplos autênticos apenas colhidos da Literatura Brasileira, apresentando-se sempre entre aspas e abonando um uso ideal. Neles, sublinha-se o termo contextualizado, que pode substituir a definição apresentada.

Os exemplos inventados, na maioria dos casos, funcionam para ilustrar construções sintáticas mais comuns em duas situações:

1. As construções sintáticas mais comuns se relacionam a verbos que possam apresentar alguma dificuldade, como "esquecer":

es.que.cer T.i. 7. Esquecer (1): Ela não esquecen de telefonar para o amigo no dia de seu aniversário.

2. ou que apresentem significado diferenciado, conforme sua regência, como "assistir":

as.sis.tir v. t.i. 1. Estar presente; comparecer: Assisti à cerimônia. (Ferreira, 2001)

Em Mattos (2005), os exemplos, em itálico, são abundantes, claros e funcionais, embora nem sempre apareçam atrelados a acepções que são oportunas. Entre os dicionários analisados, somente Mattos (2005), com muita frequência, apresenta exemplos inventados, enquanto os demais lexicógrafos estudados 
se utilizam esporadicamente de qualquer tipo de exemplo, inventado ou autêntico.

É de Mattos (2005) um caso de exemplo de uso caracterizado como inventado:

Entrante amf. Que está entrando ou começando - $O$ ano entrante deve ser melhor que este.

O exemplo acima é inventado, pois não foi extraído de um corpus, entendido aqui como um conjunto de elementos linguísticos colhido em textos reais. Mattos (2005) apresenta farta exemplificação assumindo várias funções. Algumas se expressam, porém, como fragmentos curtos de frase, apenas para expressar as combinações usuais, como no exemplo:

Revista sf. Ato de revistar $-A$ revista das bagagens / $A$ revista dos passageiros. (Mattos, 2005)

Titular amf. ou smf. 1. Que atingiu o posto mais alto da carreira de professor universitário - Um professor titular / um titular. (Mattos, 2005)

Exemplos adaptados. São aqueles extraídos de corpora, mas adaptados pelo lexicógrafo. São considerados por alguns teóricos, como Binon e Verlinde (2000: 106), "mais esclarecedores, mais significativos, mais prototípicos e menos efêmeros". Drysdale (1987, citado por Santos, 2006: 33) também opta pelos exemplos adaptados. Para este autor, mesmo em uma grande base de dados, é difícil encontrar exemplos que reúnam as condições necessárias para ilustrar os usos específicos, as restrições e as colocações, e que estejam no nível de compreensão do estudante.

Há uma polêmica em torno da questão: se os exemplos deveriam ser autênticos ou inventados. Para Fox (citado por Calderón Campos, 1994: 66), não há dúvida da superioridade dos exemplos autênticos frente aos inventados. Dessa opinião, compartilham Sinclair (1991), Martinez de Sousa (1995) e tantos outros. Sinclair $(1984,1987,1991)$ (citado por Calderón Campos, 1994), por exemplo, chega a afirmar:

No mundo dos lexicógrafos, polariza-se em dois extremos: por um lado, aqueles 'incautos' que se atrevem a incluir exemplos inventados em seus dicionários; e frente a estes, o lexicógrafo 'competente', que somente recorre a exemplos reais, extraídos do corpus com que trabalha. (Sinclair citado por Calderón Campos (1994: 67) (tradução minha) 
Outros autores, porém, posicionam-se a esse respeito de forma bem diferente. Conforme Laufer (1992, citado por Calderón Campos (1994: 167), os exemplos inventados, ainda que menos naturais, serão didaticamente mais úteis, pois se caracterizam por serem mais fáceis de entender, posto que as necessidades dos usuários são levadas em conta. Para muitos teóricos, a única vantagem de se utilizar exemplos inventados é que o lexicógrafo pode focalizar exatamente o ponto linguístico que deseja ilustrar.

Calderón Campos (1994) pondera em relação a essas discussões extremadas:

De todas as formas, a polêmica em torno da autenticidade dos exemplos me parece um problema secundário. O que é verdadeiramente importante é que os exemplos sejam representativos, naturais, imitáveis e levem à curiosidade e ao interesse dos alunos e dos usuários, de um modo geral, a utilizar novas palavras. Se conseguirmos atingir esses objetivos, pouco importa que os exemplos sejam inventados ou autênticos. (Calderón Campos, 1994: 68) (tradução minha)

O que talvez fosse interessante, diante da questão acima levantada, seria o fato de, no caso de se optar por exemplos inventados, submetê-los a controle, com o recurso simples de testá-los junto a falantes nativos (Hernández, 1989: 90).

Seja qual for o posicionamento assumido por esses autores em relação aos critérios que devem ou não ser adotados para a seleção dos exemplos, o que hoje não se discute é a respeito da necessidade de apresentar exemplos de uso no dicionário destinado ao escolar. Pérez (2000: 50) afirma que "um dicionário sem exemplos é um dicionário mais pobre". $\mathrm{Na}$ introdução do Le Petit Robert, aparece um comentário enfático sobre exemplo de uso: "[...] não é verdadeiro um dicionário sem exemplo".

No entanto, não se deve pensar que o dicionário adquira características pedagógicas por encher-se de exemplos. De nada vale sua presença sem desempenhar uma função essencial no conjunto da acepção.

Os bons exemplos são fundamentais na construção das informações, mas só se pode considerar-lhes bons "os representativos, naturais, imitáveis, que suscitem a curiosidade e o interesse" (Calderón Campos, 1994: 68).

Vale acrescentar, ainda, que a redação de exemplos de uso deverá ser em forma de enunciados completos, não muito curtos, contextualizados. Além disso, seu número não deve ser nem deficitário e nem excessivo (Damim, 2005: 78). 


\section{Quanto à estrutura textual}

De acordo com sua estrutura textual, López (2002) divide os exemplos em dois grupos: os que constituem enunciados e os que se reduzem a fragmentos de orações. Estes últimos, por sua vez, são formados por colocações ou sintagmas lexicalizados (ou formações sintagmáticas). Em Mattos (2005):

- Colocações e sintagmas lexicalizados

Em alguns casos, se usam exemplos curtos para ilustrar combinações usuais, como em Ferreira (2001) e Mattos (2005), respectivamente:

aus.te.ro (té) adj. 3. Grave, ponderado: tom austero. (Ferreira, 2001);

Revista sf. Ato de revistar $-A$ revista das bagagens. (Mattos, 2005)

- Enunciados

Entrante amf. Que está entrando ou começando - $O$ ano entrante deve ser melhor que este.

A maioria dos metalexicógrafos reconhece que um enunciado como os acima citados é a forma mais adequada para representar o exemplo lexicográfico, por ser capaz de contextualizar a entrada de maneira completa, tanto situacional quanto semantica e distribucionalmente.

3. Características semióticas do exemplo lexicográfico

O texto do dicionário é multimodal. Assim entendido, conforme Pontes (2009), porque é composto por mais de um modo semiótico, compreendendo elementos verbais e não verbais em sua constituição. Assim, manifestam-se, em uma página de dicionário, além do código escrito, outras formas de representação como a cor, o tamanho e o tipo da letra, a diagramação da página, a formatação do texto, a presença de ilustrações, etc. Tais formas de representação não estritamente linguísticas afetam a mensagem a ser transmitida, assumindo várias funções e sentidos; por isso, não podemos lê-lo ou consultá-lo prestando atenção apenas à mensagem escrita, pois esta coexiste com uma série de outros elementos representacionais, também semióticos. Integra-se, desse modo, o código verbal às representações visuais, entendendo que esses recursos possuem limitações e potencialidades, no dizer de Silva 
(2006). Isso significa que cada módulo semiótico determina funções comunicativas limitadas e com potencial para expressar os sentidos que sua natureza lhe permite. Para tal constatação, ilustro aqui alguns casos em que os recursos semióticos no verbete significam.

Inicialmente, é importante fazer algumas considerações a respeito do arranjo do exemplo na composição do verbete.

Os exemplos, normalmente, no material em análise, situam-se imediatamente depois da acepção com a grafia estabelecida por cada dicionário. Para distinguir os elementos que compõem um verbete, usam-se diferentes tipos de letras. No caso particular do exemplo lexicográfico, Ferreira (2001, 2005) marca-o em letras do tipo itálico, conforme os exemplos citados. Além disso, apresenta dois pontos (:) para separá-lo da definição. Quando ocorre um exemplo autêntico, marca-o por aspas para indicar que não é de sua autoria. Também destaca a palavra que quer ilustrar o uso sublinhando-a. Todos esses recursos significam e ajudam o leitor a acessar a informação que deseja de forma mais rápida.

Mattos (2005), nos exemplos também citados, apresenta tipograficamente o exemplo em itálico e se utiliza de um traço (-) para separá-lo da definição, porém não faz nenhum destaque para a palavra que ilustra. Rocha (2001), ao contrário de Ferreira (2001, 2005) e Mattos (2005), não apresenta o exemplo em itálico e esse se materializa também em um enunciado independente, só que desconectado por um ponto (.) dos aspectos definitórios, demonstrando assim que informação enciclopédica e traços semânticos se distinguem.

Vale observar que o exemplo em Rocha (2004), na maioria dos casos, funciona com informações enciclopédicas. Há outro traço que deve ser salientado neste dicionário: a palavra-entrada, ilustrada no exemplo, se apresenta negritada, diferente de Ferreira (2005), que o faz sublinhando.

O exemplo se apresenta, em todos os dicionários, visualmente bem saliente $^{4}$ em relação à definição, escrita em letra cursiva comum. Sendo o exemplo uma informação nova (portanto, remática (Silva, 2006) mais recente do que a definição lexicográfica, igualmente remática, teria que ser mais destacado para se adequar ao contexto da nova prática pedagógica de ensino de línguas que nascia, com muito peso, por ter como base a concepção de

4 Segundo Kress e Van Leeuwen (2006: 177), a saliência é um poderoso recurso visual por meio do qual certos elementos de um texto são dispostos de modo a chamar a atenção do leitor. Vários são estes recursos, pode-se citar: a disposição dos elementos em planos diferentes; os distintos tipos e tamanhos de letras e a qualidade do contraste e da cor, por exemplo. 
linguagem como concreta e de natureza social. Hoje, na Lexicografia brasileira, esta prática pode também ser observada nos dicionários escolares. Assim, a influência da nova Lexicografia britânica, iniciada com Hornby (1948), sobre os dicionários escolares brasileiros foi, posteriormente, perceptível, pois até há pouco tempo havia uma ausência quase total de exemplos e fraseologias, como se pode conferir no minidicionário de Ferreira (1977). Ainda se pode observar que cada autor toma decisões diferenciadas em relação aos recursos semióticos, motivados por princípios teóricos ou pedagógicos, não tendo, pois, o dicionário um padrão universal; dentro de cada dicionário, porém, suas decisões são uniformes para definir uma convenção - estratégia retórica utilizada para manter o usuário numa relação contínua com o livro de consulta, garantido assim a familiarização do usuário ao longo de sua escolarização.

Sobre as formas de saliência visual que identificam o exemplo, Pontes (2009) afirma que tais destaques têm razão de ser na medida em que indicam uma função diferente daquela específica à definição e aos demais paradigmas. Conclui-se assim que os aspectos semióticos não aparecem no texto com fins meramente estéticos, mas também para significar. Na maioria dos casos, os lexicógrafos destacam, no interior do exemplo, a palavra-entrada por meio de algum símbolo.

Fariñas (2001) critica os dicionários escolares por não darem um tratamento satisfatório ao exemplo na parte introdutória do dicionário; restringem-se a apresentar informações como "há exemplos de uso em todas as acepções" ou "muitas definições levam exemplos", quando deveriam, convenientemente, instruir os consulentes a encontrar uma palavra no dicionário a partir da amostra clara do uso do termo a ser consultado. Também seria recomendável que se falasse sobre como se procedeu a escolha para compor os verbetes do dicionário ou sobre alguns aspectos relativos a sua elaboração.

\section{Nenhum exemplo}

Vale dizer ainda que os autores estudados registram, como entrada, terminologias, fraseologias, estrangeirismos, variantes regionais e variantes populares, porém, em geral, essas unidades léxicas não são exemplificadas. Isso ocorre por reconhecê-los como fato de língua, mas entendem que devam ser evitados nos contextos reais de comunicação formal, refletindo assim uma concepção normativa ou purista. Barros (2000: 78), falando de alguns tipos de variantes no contexto da Lexicografia, coloca que há usos que não estão contemplados nos dicionários, nem mesmo para serem condenados. 
Em relação à ausência de exemplos para ilustrar terminologias técnicas, Toope (1996) explica que os autores, em geral, não trazem exemplos para o termo quando há um referente simples e um campo limitado de aplicação. Apontaria ainda um outro motivo. Parece-me que pelo fato de os termos técnicos serem considerados monossêmicos, não trazem problemas para seu uso, até porque os termos, dentro de uma visão clássica da Terminologia, são usados por especialistas no diálogo com seus pares, não tendo espaço, no dicionário escolar, para o seu registro. Desse modo, cabe ao aluno apenas compreender o verdadeiro significado das terminologias, tendo em vista somente a compreensão dos textos escolares.

\section{Considerações finais}

O exemplo, em sua função decodificadora, apresenta informações semânticas pertinentes à compreensão de unidades léxicas, que funcionam como entrada de verbete. Isso significa que não apenas a definição traz informações semânticas importantes para a compreensão, mas outros paradigmas, como o exemplo de uso, também traz informações necessárias à produção do sentido no âmbito do verbete, entendido aqui como texto. Daí ReyDebove (1971) afirmar que a definição incompleta que é apoiada em exemplos, torna-se completa graças ao exemplo, de modo que os traços distintivos da coisa definida encontram-se repartidos entre a definição e o exemplo.

Em termos de importância, o exemplo de uso acumula várias funções, como as apresentadas, para ajudar o consulente não apenas a compreender as palavras que busca, mas também a saber como usá-las num contexto real de comunicação. Desse modo, o dicionário cumpre a importante função de produção e de compreensão, dentre várias outras.

Alguns pontos importantes sobre os exemplos lexicográficos:

1. Quando usados, costumam ser apresentados assistematicamente, ou seja, apresentam-se para algumas acepções e para outras não; ou então assumem poucas funções ou nenhuma no interior do verbete;

2. Não ilustram as fraseologias, quando se apresentam como subentradas, consequentemente não ajudam o consulente a empregá-las, como se pode ver em Mattos (2005) e em Ferreira (2001, 2005);

3. Em alguns casos, ilustram informações sintáticas, como em Mattos (2005), sem aparecer, explicitamente, noutro paradigma, as regras de caráter metalinguístico sobre o fato gramatical em questão; 
4. Na maioria dos casos, são apresentados em frases curtas (ou segmentos de enunciado), em colocações, em sintagmas lexicalizados (Ferreira (2001, 2005) e Mattos (2005);

5. Alguns autores apresentam muitos exemplos, porém não acrescentam nenhuma informação à explicação do significado definido;

6. Quando aparecem, são, em geral, inventados e raramente autênticos. Em outros, as edições mais recentes tendem a diminuir o número de exemplos autênticos, em geral, colhidos em textos literários;

7. Os autores selecionados para a análise não costumam valorizar o exemplo. Tal carência reflete-se nas introduções: não recomendam sua leitura aos consulentes, resumindo-se a definir o paradigma "exemplo" e "onde encontrá-los", como o faz Aulete (2005);

8. Os exemplos não são iguais do ponto de vista de recursos tipográficos em todos os dicionários estudados;

9. Alguns autores brasileiros se restringem a apresentar exemplos com uma única função: a de apenas ilustrar fatos sintáticos ou informações enciclopédicas;

10. Há, entre os autores estudados, como Bueno (2000) e Rocha (2004), os que não apresentam exemplos de uso, e há ainda aqueles, como Mattos (2005), que incluem exemplos com as mais variadas funções, o que é algo positivo no contexto da Lexicografia moderna.

Referências bibliográficas

AUROUX, S. A.. 1992. Revolução tecnológica da gramatização. Campinas: Ed. da Unicamp.

BAYLON, C.; FABRE, P. 1994. La Semántica. Barcelona: Paidós.

BARROS, D. L. P. de. 2000. O discurso do dicionário. Alfa 40. 75-96. Tema central: Léxico - Estudos lexicológicos e lexicográficos.

BERDET, E. 1996. Lengua, sociedad y diccionario. En: Léxico e diccionarios. Tarrogana: Universitat Rovira i Virgili. p.71-90.

BINON, J.; VERLINDE, S. 2000. A contribuição da Lexicografia pedagógica à aprendizagem e ao ensino de uma língua estrangeira ou segunda. In: LEFFA, V. J. (org.) As palavras e sua companbia: o léxico na aprendizagem das línguas. Pelotas: EDUCAT.

CUNILL, E. L. 2004. Los ejemplos. En: CUNILL, E.L; CALERO FIDEZ, M.A.; BERDET, E.F.(Org.) De mujeres y diccionarios. Evolución de lo femenino en la 22a. edición del DRAE.

CALDERÓN CAMPOS, M. 1994. Sobre la elaboración de diccionarios monolíngues de producción, las definiciones, los ejemplos y las colocaciones léxicas. Granada: Universidad de Granada.

DAMIM, Cristina. 2005. Proposição de critérios metalexicográficos para avaliação do dicionário escolar. Dissertação (Mestrado em Letras). Universidade Federal do Rio Grande do Sul.

DUBOIS, J.; DUBOIS, C. 1971. Introduction à la lexicographie: le dictionnaire. Paris: Larousse. 
ESCRIBANO, C. 2003. La microestrutura del diccionario: las informaciones lexicográficas. En: GUERRA, A.M.M. A. (Org.) Lexicografía española. Barcelona: Ariel Lingüística. p.103-26. EZGUERRA, M. 1982. Diccionario y gramatica. Revista Española de Lingüística Actual IV. p 154-207.

FARIÑAS, L. F. A. 2001. Las Presentaciones de los diccionarios escolares. Breve historía de un elemento didáctico olvidado por las editorales, los profesores y los usuarios. Glosas Didáticas 6. Disponível em: http://sedll.org/doces/publicaciones/glosas/n6/alzola.html.

FORGAS BERDET, E. 1996. Lengua, sociedad y diccionario. En: FORGAS BERDET, ESTHER (org). Léxico e diccionarios. Tarrogana: Universitat Rovira i Virgili. p.71-90.

GELPÍ ARROYO, C. 2000. La Lexicografia. Barcelona: Grupo Santillana de Editores, S.A.

; CASTILlo, N. 2004. As definições de conceitos especializados em dicionários monolíngues. Cadernos de Tradução. A terminologia em Foco 17. 129-36.

HERNÁNDEZ, H. 1989. Los diccionarios de orientación escolar: contribuición al estudio de la lexicografía monolingüe española. Tubingen: Max Niemeyer Verlag.

1994. El diccionario entre la Semantica y las necesidades de los usuários. In: Aspectos

de Lexicografía Contemporánea. Barcelona: Vox Biblograf.

HUMBLÉ. 2001. Dictionaries and language leaners. Frankfurt am Main: Haag und Herchen.

KRESS, G.; LEEUWEN, T van. 2006. Reading images: the grammar of visual design. New York: Routledge.

LARA, L. F. 1996. Teorías del Diccionario monolingue. Mexico: El Colégio de México.

LÓPEZ, J. L. Los términos de la Física en los diccionarios generales y especializados. Tese (doutorado em Filologia) Lérida, Universidad de Lérida,2002. Disponível em: http:// www.tesisenxarxa.net/TESIS_UdL/AVAILABLE/TDX-0821103-125440/

MARTIN, M. del C. 2000. El diccionario en el aula. Granada: Universidad de Granada.

MARTIN-ROULEDGE, V. 1997. L'utilité des exemples des exemples dans les dictionnaires bilingues français-anglais pour les étudiants en traduction. In : Problèmes et méthodes de la lexicographie québecoise. Québec: Centre International de Recherche en Aménagement Linguistique.

MARTINEZ DE SOUSA, J. 1995. Diccionario de lexicografía práctica. Barcelona: Bibliograf. PÉREZ, E. 2000. Diccionarios. Introducción a la historia de la lexicografía del español. Ediciones Trea, S.L.

PONTES, A. L. 2009. Dicionário para uso escolar: Que é e como se faz. Fortaleza: Ed. Universidade Estadual do Ceará.

PORTO DAPENA, J.Á. s/d/.Manual de técnica lexicográfica. Madrid: Arcos Libros S.L.

Disponível em: http://www.udc.es/grupos/lexicografia/diccionario/Planta.htm

REY-DEBOVE, J. 1971. Étude linguistique et semiotique des diccionnaires françaises contemporaines. Paris: Hachette.

SANTAMARÍA PÉREZ, M. Isabel. 2000. Tratamiento de las unidades fraseológicas en la lexicografía bilíngue español-catalán. Tese (Doutorado em Filologia). Universidad de Alicante.

SANTOS, M. G. B. dos. 2006. Análise de exemplos no dicionário bilíngue de uso português-espanhol (DIBU). Dissertação (Mestrado em Linguística). Universidade Federal de Santa Catarina.

SILVA, L. F. P. da. 2006. Estudo crítico da representação visual do léxico em dicionários infantis ilustrados. Dissertação (Mestrado). Universidade de Brasília. 
370 Antonio Luciano Pontes

SOBRINHO, J. C. 2000. Uso de dicionário: configurando estratégias de aprendizagem de vocabulário. In: LEFFA, J. V. (org.). Palavras e sua companhia: o léxico na aprendizagem. Pelotas: ALAB.

TOOPE, M. 1996. Examples in the bilingual dictionary. Tese (Doutorado). Universidade de Ottawa.

Fontes

AULETE, C. 2004. Minidicionário contemporâneo da língua portuguesa. Rio de Janeiro: Nova Fronteira.

BUENO, S. 2000. Minidicionário da lingua portuguesa. São Paulo: FTD. (ed. rev. e atual).

FERREIRA, A. B. de H. 2001. Miniaurélio Século XXI. 5 ed.rev. e ampliada. Rio de Janeiro: Nova Fronteira.

FERrEIRA, A. B. de H. 2005. Miniaurélio. 6 ed.rev. e atual. Curitiba: Positivo. 2008. Miniaurélio. 7 ed.rev. e atual. Curitiba: Positivo.

MATTOS, G. 2005. Dicionário Júnior da língua portuguesa. 3 ed. São Paulo: FTD.

ROCHA, R. 2005. Minidicionário da lingua portuguesa. São Paulo: Scipione. 